\title{
Effectiveness of Perineal Massage in the Second Stage of Labor in Preventing Perineal Trauma
}

\author{
Suleyman Cemil OGLAK ${ }^{1}$, Mehmet OBUT ${ }^{2}$ \\ Diyarbakir, Turkey
}

\section{ABSTRACT}

OBJECTIVE: This study was aimed to investigate the effect of perineal massage in the second stage of labor in prevention perineal traumas during childbirth.

STUDY DESIGN: This observational study was conducted with 171 nulliparous women delivered by vaginally between January 2017 and May 2019. All the patients managed by the selective episiotomy principle. All the patients were divided into two groups: the perineal massage group and the control group. The perineal massage was performed during the second stage of labor until the baby's head was birth. The control group received routine labor care. In the case of threatening tears in any patient and at the preference of the midwife, mediolateral episiotomy was performed. Following childbirth, the perineum and vagina were examined for perineal tears and episiotomy by the midwives.

RESULTS: The length of the second stage of labor was significantly lower in the massage group (36 \pm 19 minute) compared with the control group ( $46 \pm 25$ minute, $p=0.024)$. Twenty-five women $(28.8 \%)$ in the massage group had intact perineum after vaginal birth, compared with five $(6.0 \%)$ in the control group $(p=0.003)$. The rate of first- and second-degree perineal tears are higher in the massage group [28 patients $(32.2 \%)$ and 9 patients $(10.3 \%)$, respectively] than in the control group [10 patients $(11.9 \%)$ and 5 patients $(6.0 \%)$, respectively, $p<0.001]$. The incidence of episiotomy was significantly lower in the massage group (25 patients, $28.7 \%$ ) than in the control group (64 patients, $76.1 \%, p<0.001$ ).

CONCLUSION: Perineal massage should be considered a routine intervention to reduce the incidence of perineal trauma.

Keywords: Nulliparity, Perineal massage, Perineal trauma, Selective episiotomy

Gynecol Obstet Reprod Med 2020:26(2)88-93

\section{Introduction}

One of the leading reasons for the increase of elective cesarean section (CS) rates in Turkey is the concern about pelvic trauma during childbirth (1). Perineal trauma affects most

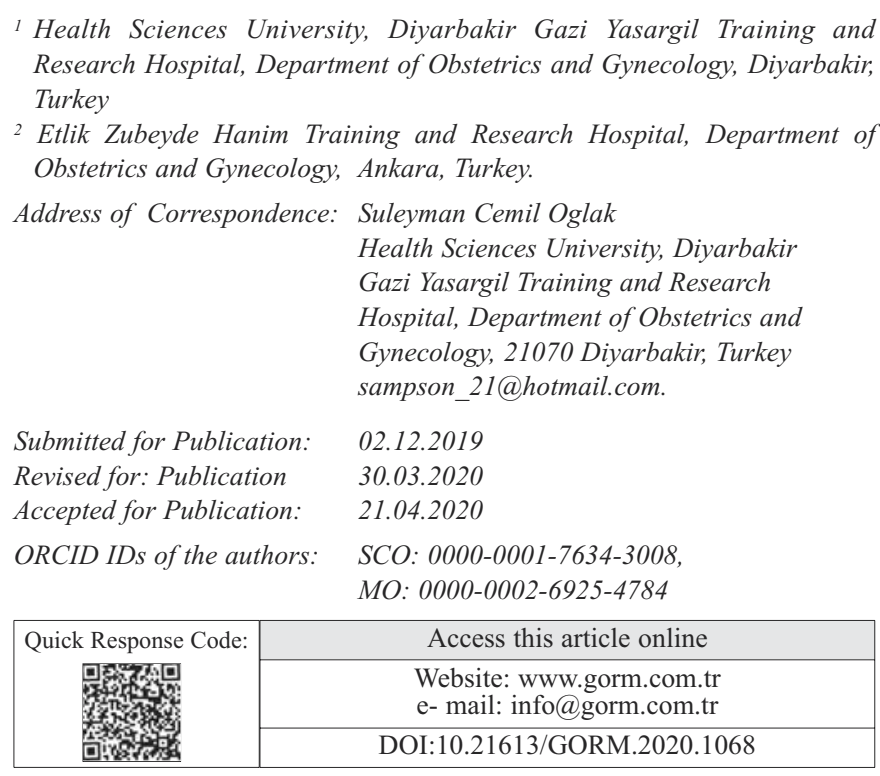

How to cite this article: Oglak SC. and Obut M. Effectiveness of Perineal Massage in the Second Stage of Labor in Preventing Perineal Trauma. Gynecol Obstet Reprod Med. 2020:26(2)88-93 women during childbirth, especially during the first vaginal birth. Perineal trauma described as any damage to the genital tract during childbirth. It can occur as a spontaneous tear when the baby is exiting, or as a surgical incision, known as episiotomy, or both (2). $85-91 \%$ of women have experienced degrees of birth trauma $(3,4)$. Over two-thirds of such women required suturing (5). The risk factors for perineal tears are nulliparity, Asian ethnicity, macrosomia, shoulder dystocia, occiput-posterior position, instrumental delivery and prolonged second stage of labor (6). Perineal injuries are associated with short-term and long-term complications such as postpartum hemorrhage, hematoma, infection, dyspareunia, delayed time to sexual intercourse, persistent perineal pain, and urinary and fecal incontinence (7). All these morbidities can adversely affect postpartum recovery feeling, maternal bonding with her baby, breastfeeding and sexual activity.

Despite the recommendation of the World Health Organization that episiotomy is restricted to $10 \%$ of vaginal births, this procedure is still practiced frequently, being performed in approximately $60 \%$ of vaginal deliveries (8). An episiotomy is widely used in Asian countries due to the shortness and tenacity of the perineum in Asian women (9). The rate of episiotomy, which is about $10 \%$ in Northern Europe, is 
almost $100 \%$ in East Asia (10). In a recent study, it was reported that $52 \%$ of women who gave birth via vaginal delivery underwent episiotomy in Turkey (10). However, it has been shown in several studies that episiotomy, which was thought to be a protective method for a long time, increases the risk of third and fourth-degree perineal tears, hemorrhage, prolonged postpartum pain, dyspareunia, and late perineal healing (1113). Moreover, anal incontinence is higher in patients who underwent episiotomy than those with spontaneous perineal tears by 1.7-2.6 times (14). All these evidence justify the recommendation that episiotomy should not be routinely performed in vaginal delivery (15). However, in several studies of restricted use of episiotomy, $51-77 \%$ of the women sustained perineal trauma that required suturing (16). For these reasons, proper interventions are needed to reduce the risks associated with episiotomy and perineal tears. Furthermore, it was reported that the women who delivered with an intact perineum complaint less perineal pain shortly after delivery and experienced less dyspareunia within 3 months of postpartum (17).

Perineal massage in the second stage of labor is determined to reduce the risk of perineal trauma from an episiotomy or spontaneous tears by extending the vaginal tissues, relaxing the perineum and increasing the blood supply to the perineum (18). However, the results of some studies indicate that perineal massage provides no advantage or disadvantage in reducing obstetric perineal trauma (19). Regarding the conflicting results on the effectiveness of perineal massage in the second stage of labor, this study was aimed to investigate the effect of perineal massage in the second stage of labor in prevention perineal traumas during childbirth.

\section{Material and method}

This observational study was conducted with 171 nulliparous women delivered by vaginally in Diyarbakir Gazi Yasargil Training and Research Hospital Department of Obstetrics and Gynecology between January 2017 and May 2019. All the patients managed by the selective episiotomy principle that episiotomy is unnecessary even in situations in which the literature suggests that it may confer some benefit (20). Therefore, no episiotomy was performed to the patients except under exceptional circumstances, those in which clinical judgment would deem the episiotomy absolutely necessary. The inclusion criteria for participation in this study were as follows: age of 18-30 years, gestational age of 38-42 weeks, cephalic presentation, and singleton pregnancy. The exclusion criteria were as follows: multiparity, multiple gestation, fetal distress during delivery, assisted childbirth (vacuum or forceps), failure to progress in labor, evidence of any contraindications to vaginal delivery, administration of pethidine hydrochloride, history of precipitate labor, previous cesarean section, history of any vaginal surgical procedure, receiving a perineal massage during the antenatal period of the current pregnancy, vaginal herpes, patients' withdrawal from continu- ing the perineal massage and macrosomia $(>4500 \mathrm{~g})$. Ethical approval for the study was obtained from the Ethics Committee of Gazi Yasargil Training and Research Hospital. Informed consent forms were obtained from all participants. The study was conducted in accordance with the Declaration of Helsinki.

All the patients were divided into two groups: the perineal massage group and the control group. The experienced midwives performed all deliveries. All the midwives were instructed to perform the perineal massage during the second stage of labor while the baby's vertex was in the crowning position in the perineal massage group. The midwives performed the massage to the perineum with a gentle up-down and sideto-side pressure toward rectum between 3 o'clock and 9 o'clock positions (U-shaped reciprocating movement) after wearing sterile latex gloves and lubricating their index and middle fingers using a hypoallergenic lubricant (liquid vaseline). The perineal massage was performed during the uterine contractions and continued until the baby's head was birth. The massage discontinued if the patient felt pain or burning, and resumed when the patient was ready. The control group received routine labor care. In the case of threatening tears in any patient and at the preference of the midwife, mediolateral episiotomy was performed. Following childbirth, the perineum and vagina were examined for perineal tears and episiotomy by the midwives. All of the perineal suturing was performed by midwives. All patients received routine postpartum care.

Participants' baseline data included age, body mass index (BMI), gestational age at delivery (weeks) and abortion history. For all participants, the following additional parameters were also evaluated: baby's gender, occiput anterior or posterior presentation, neonatal weight and the length of the second stage of labor. Perinatal outcomes were classified into the following: intact perineum, perineal tears and degree thereof, and performance of an episiotomy. First-degree perineal tear describes the laceration of the vaginal mucosa or perineal skin only. Second-degree perineal tear involves the perineal muscles. Third-degree perineal tear involves the anal sphincter muscles. Fourth-degree perineal tear extends through the anal epithelium (6). The primary outcomes of this study were the comparison of the rate of perineal tears and episiotomy during childbirth between the groups.

\section{Statistics}

SPSS 16.0 for Windows (SPSS Inc., Chicago, IL, USA) was used for statistical analysis. Numerical data were expressed as mean and standard deviation, and categorical data were expressed as frequency and percentage. The comparison of categorical data in the groups was made with Chi-square and Fisher exact tests. The comparison of quantitative variables was made with Independent Samples $t$-Test. In all comparisons, $p<0.05$ was considered statistically significant. 


\section{Results}

A total of 171 eligible nulliparous women were recruited for the study. Of the 171 participants, 87 were in the massage group, while 84 were in the control group. Episiotomy was only performed to the patients under exceptional circumstances, those in which clinical judgment would deem the episiotomy necessary (selective episiotomy principle).

There were no statistically significant differences between the two groups regarding their baseline characteristics, including maternal age, pre-pregnancy weight, height, weight gain during pregnancy, BMI and previous abortion (Table I).

Delivery characteristics and neonatal outcomes of the patients are summarized in table II. All the patients were between the gestational ages of 38-42 weeks. Patients with a birth weight below 2500 grams and over 4500 grams were excluded from the study. There was no significant difference between the two groups in terms of gestational age and birth weight. All the fetuses were cephalic presentation. In the second stage of labor, 84 of 87 (96.5\%) fetuses were diagnosed as being in the occiput anterior position in the massage group compared with 82 of $84(97.6 \%)$ in the control group. This difference was not statistically significant $(p=0.552)$. When the neonatal follow-up features of infants in the study and control groups were examined, there was no statistical difference between the terms of 1-minute Apgar scores $(\mathrm{p}=0.320)$ and 5minute Apgar scores $(\mathrm{p}=0.350)$. The Apgar scores for all newborns in both the groups were over 7 on 1- and 5-minute.

The length of the second stage of labor was significantly lower in the massage group ( $36 \pm 19$ minute) compared with the control group ( $46 \pm 25$ minute, $\mathrm{p}=0.024)$.

The perineal outcomes of the patients are shown in table III. Twenty-five women (28.8\%) in the massage group had intact perineum after vaginal birth, compared with five $(6.0 \%)$ in the control group. This difference was statistically significant

Table I: Baseline characteristics of the patients

\begin{tabular}{lccc}
\hline & Massage group $(\mathrm{n}=87)$ & Control group $(\mathrm{n}=84)$ & $p$ \\
\hline Age (years) & $20 \pm 3$ & $21 \pm 3$ & 0.122 \\
Pre-pregnancy weight $(\mathrm{kg})$ & $57 \pm 11$ & $59 \pm 13$ & 0.541 \\
Height $(\mathrm{cm})$ & $158 \pm 8$ & $160 \pm 6$ & 0.640 \\
Weight gain during pregnancy $(\mathrm{kg})$ & $14 \pm 5$ & $14 \pm 6$ & 0.662 \\
BMI $\left(\mathrm{kg} / \mathrm{m}^{2}\right)$ & $25.5 \pm 6.2$ & $24.9 \pm 5.3$ & 0.482 \\
Previous abortion, $\mathrm{n}(\%)$ & $10(11.4 \%)$ & $11(13.0 \%)$ & 0.451 \\
\hline
\end{tabular}

Table II: Delivery characteristics and neonatal outcomes of the patients

\begin{tabular}{lccc}
\hline & Massage group ( $\mathrm{n}=87)$ & Control group $(\mathrm{n}=84)$ & $p$ \\
\hline Gestational age (weeks) & $39 \pm 1.1$ & $39.5 \pm 0.9$ & 0.211 \\
Occiput anterior, $\mathrm{n}(\%)$ & $84(96.5 \%)$ & $82(97.6 \%)$ & 0.552 \\
Occiput posterior, $\mathrm{n}(\%)$ & $3(3.5 \%)$ & $2(2.4 \%)$ & 0.632 \\
Neonatal weight (g) & $3.350 \pm 0.45$ & $3395 \pm 0.35$ & 0.425 \\
Length of the second stage of labor (min) & $36 \pm 19$ & $46 \pm 25$ & $0.024^{*}$ \\
Male fetus, $\mathrm{n}(\%)$ & $45(51.7 \%)$ & $43(51.1 \%)$ & 0.533 \\
1-minute apgar score & $8.7 \pm 0.5$ & $8.9 \pm 0.3$ & 0.320 \\
5-minute apgar score & $9.8 \pm 0.2$ & $9.8 \pm 0.3$ & 0.350 \\
\hline
\end{tabular}

*: $p<0.05$

Table III: Perineal outcomes of the patients

\begin{tabular}{|c|c|c|c|}
\hline & Massage group $(n=87)$ & Control group $(n=84)$ & $p$ \\
\hline Perineal status & & & $0.003^{* *}$ \\
\hline Perineal trauma, $\mathrm{n}(\%)$ & $62(71.2 \%)$ & $79(94.0 \%)$ & \\
\hline Intact perineum, n (\%) & $25(28.8 \%)$ & $5(6.0 \%)$ & \\
\hline Perineal trauma type & & & $<0.001^{* * *}$ \\
\hline First-degree tear & $28(32.2 \%)$ & $10(11.9 \%)$ & \\
\hline Second-degree tear & $9(10.3 \%)$ & $5(6.0 \%)$ & \\
\hline Episiotomy & $25(28.7 \%)$ & $64(76.1 \%)$ & \\
\hline
\end{tabular}

${ }^{* *}: p<0.01,{ }^{* * *}: p<0.001$ 
( $p=0.003$ ). The results revealed $32.2 \%$ ( 28 patients) of firstdegree perineal tear and $10.3 \%$ ( 9 patients) of a second-degree perineal tear in the massage group. There were $11.9 \%$ (10 patients) of first-degree perineal tear and $6.0 \%$ (5 patients) of a second-degree perineal tear in the control group. In the massage group, in 22 patients with a first-degree perineal tear and 6 patients with a second-degree perineal tear, the laceration was in the anterior vaginal wall. Of these 22 patients with the first-degree perineal tear, 20 patients $(90.9 \%)$ did not require suturing, and these tears were left for secondary healing. The incidence of episiotomy was significantly lower in the massage group $(28.7 \%, 25$ patients) than in the control group $(76.1 \%, 64$ patients, $p=0.001)$. Neither of the groups suffered from severe (third- and fourth-degree) perineal tears.

\section{Discussion}

The results of this study indicated that perineal massage in the second stage of labor reduces the length of the second stage of labor, increases the rates of intact perineum and decreases the rates of episiotomy.

Many patients may prefer elective CS for fear of perineal trauma during childbirth. However, CS also has maternal and fetal complication risks, and it is an economic burden on individuals and the countries (21). Based on the ecological studies, CS prevalence between $9-19 \%$ has been associated with better maternal and perinatal outcomes (22). Overall CS rate is $51.2 \%$ in Turkey. This rate is far above the global rate of $18.6 \%$ (23) and the recommended rate of $9-19 \%$. Given the high birth rate in our country, proper interventions are needed to promote vaginal birth.

Perineal massage is one of the appropriate interventions. It has been reported that perineal massage in the second stage of labor decreases perineal trauma rates by reducing stress and pressure, increasing the relaxation of perineal muscles and perineal blood flow (18). However, results from previous studies on the effect of perineal massage on preventing the perineal trauma during childbirth have been conflicting. In the study of Albers et al., perineal trauma rates were $76.7 \%$ in the warm compresses group, $76.7 \%$ in the massage group, and $77.7 \%$ in the control group. They reported that warm compress or massage provides no apparent advantage in reducing perineal trauma (19). In the study of Zare et al., the rates of an intact perineum, perineal tear and episiotomy were $22.2 \%$, $33.3 \%$, and $44.4 \%$ in the massage group and $20.2 \%, 28.3 \%$, and $49.3 \%$ in the control group, respectively. This difference was not significant, and they stated that the perineal massage in the second stage of labor was not effective in the reduction of perineal trauma (24). In a randomized clinical trial by Geranmayeh et al., intact perineum and episiotomy rates were $27 \%$, and $45 \%$ in the massage group and $4 \%$, and $88 \%$ in the control group, respectively. They indicated that the perineal massage in the second stage of labor increases the intact per- ineum, mainly by decreasing the rates of episiotomy (18). In a recent study, the frequency of episiotomy was $69.47 \%$ in the massage group and $92.31 \%$ in the control group. Also, the results revealed higher perineal trauma rates in the control group than the massage group. Regarding these results, they reported that perineal massage in the second stage of labor reduced the need for episiotomy, perineal injuries, and perineal pain (25). In this study, we found a significant benefit of perineal massage concerning the rate of perineal trauma among nulliparous women. The intact perineum rates were significantly higher in the massage group than the control group $(28.8 \%$ and $6.0 \%$, respectively, $p=0.003$ ). The increase in the intact perineum rates was mainly related to the decrease in episiotomy rates. Episiotomy rates were $28.7 \%$ in the massage group, and $77.1 \%$ in the control group $(p<0.001)$. The rate of first and second-degree perineal tears was higher in the massage group than in the control group. The perineal tears in the massage group are mostly in the anterior part of the vagina. The effect of perineal massage on the anterior part of the vagina appears to be limited. On the other hand, $90.9 \%$ of patients with a firstdegree perineal tear in the massage group did not require suturing. Also, no third and fourth-degree perineal tears occurred in any patient in the massage group.

Geranmayeh et al. suggested that a decrease in the episiotomy rates and an increase in the first- and second-degree perineal tear rates could be associated with the delay in the decision of the midwife's episiotomy incision (18). They asserted that perineal massage could be an assuring method to decrease the rates and the related effects of episiotomy in countries with a high prevalence of episiotomy. In our study, all deliveries were managed with selective episiotomy principle, and we observed that episiotomy rates were significantly lower, and the intact perineum rates were significantly higher in the massage group than the control group. These results indicate that perineal massage is an effective method in lowering episiotomy rates while deliveries are managed with selective episiotomy principles.

The reduction in perineal trauma and episiotomy rates may likely reduce postpartum perineal pain. This effect may lead to a reduction in the use of postpartum analgesia preparations. Also, a reduction in postpartum pain improves maternal bonding with her baby. All these are factors that contribute to the healing process and shorten the length of hospital stay. As seen in this study, perineal massage reduces the length of the second stage of labor. Considering the contribution of perineal massage to the reduction of elective CS rates, it can be suggested that the cost-effectiveness of perineal massage especially crucial for low-income countries.

In several studies, perineal massage has been performed through the last weeks of pregnancy. In the study of Ugwu et al., antenatal perineal massage had started between 34-36 weeks gestation (26). The incidence of episiotomy was sig- 
nificantly lower in the massage group than in the control group ( $37.7 \%$ and $58.2 \%$, respectively). $50.9 \%$ of the patients in the massage group had intact perineum after vaginal birth, compared with $29.1 \%$ of the patients in the control group. They concluded that antenatal perineal massage reduces the likelihood of episiotomy, thereby increasing the rate of intact perineum after vaginal birth. Mei-dan et al (27) reported that although antenatal perineal massage did not increase the possibility of an intact perineum, it is probably harmless, and the patients should not be discouraged to perform it.

Episiotomy can reach to involve the anal sphincter or reduce the integrity of the perineum, by predisposing the patients to be fecal and/or flatus incontinence (26). It was suggested that a decrease in episiotomy rates reduces the risk of anal incontinence (14). In this study, no third and fourth-degree perineal tears were observed in any patient. However, patients were not followed-up in the long term.

The main limitation of this study is the fact that episiotomy's decision to avoid a perineal tear is made at the preference of the midwife. Also, increasing the number of first and second-degree tears in the intervention group could be associated with delaying episiotomy incision. The other limitation is the short duration of follow-up. In a study, it has shown that the side-lying position during childbirth decreases perineal trauma (28). Most of the studies and our study were performed in the lithotomy position.

\section{Conclusion}

Our study showed that perineal massage in the second stage of labor reduces the length of the second stage of labor, increases the rates of intact perineum and decreases the rates of episiotomy. Perineal massage should be considered a routine intervention to reduce the incidence of perineal trauma during childbirth.

\section{Acknowledgments: None.}

Funding: We did not receive funding from any institution. Author contribution: SCO: Study conception and design, acquisition of data, analysis and interpretation of data, drafting of the manuscript, critical revision. MO: Study concept and design, acquisition of data, analysis and interpretation of data.

Conflict of interest: The authors declared there is no conflict of interest.

\section{References}

1. Eyi EGY, Mollamahmutoglu L. An analysis of the high cesarean section rates in Turkey by Robson classification. $\mathrm{J}$ Matern Fetal Neonatal Med. 2019:1-11.

2. Aguiar M, Farley A, Hope L, Amin A, Shah P, ManasekiHolland S. Birth-related perineal trauma in low- and middle-income countries: A systematic review and meta- analysis. Matern Child Health J. 2019; 23(8):1048-70.

3. Smith LA, Price N, Simonite V, Burns EE. Incidence of and risk factors for perineal trauma: a prospective observational study. BMC Pregnancy Childbirth. 2013;13:59.

4. Mora-Hervás I, Sánchez E, Carmona F, Espuña-Pons M. Perineal trauma in primiparous women with spontaneous vaginal delivery: episiotomy or second degree perineal tear? Int J Women's Health Reprod Sci. 2015;3(2):84-8.

5. Kalichman L. Perineal massage to prevent perineal trauma in childbirth. Isr Med Assoc J. 2008;10(7):531-3.

6. Goh R, Goh D, Ellepola H. Perineal tears - A review. Aust J Gen Pract. 2018;47(1-2):35-8.

7. Abedzadeh-Kalahroudi M, Talebian A, Sadat Z, Mesdaghinia E. Perineal trauma: incidence and its risk factors. J Obstet Gynaecol. 2019;39(2):206-11.

8. Vieira F, Guimarães JV, Souza MCS, Sousa PML, Santos RF, Cavalcante AMRZ. Scientific evidence on perineal trauma during labor: Integrative review. Eur J Obstet Gynecol Reprod Biol. 2018;223:18-25.

9. Lam KW, Wong HS, Pun TC. The practice of episiotomy in public hospitals in Hong Kong. Hong Kong Med J. 2006;12(2):94-8.

10. Kartal B, Kizılırmak A, Calpbinici P, Demir G. Retrospective analysis of episiotomy prevalence. J Turk Ger Gynecol Assoc. 2017;18(4):190-4.

11. Committee on Practice Bulletins-Obstetrics. ACOG Practice Bulletin No. 198: Prevention and management of obstetric lacerations at vaginal delivery. Obstet Gynecol. 2018;132(3):e87-e102.

12. Jiang H, Qian X, Carroli G, Garner P. Selective versus routine use of episiotomy for vaginal birth. Cochrane Database Syst Rev. 2017;2:CD000081.

13. Vale de Castro Monteiro M, Pereira GM, Aguiar RA, Azevedo RL, Correia-Junior MD, Reis ZS. Risk factors for severe obstetric perineal lacerations. Int Urogynecol J. 2016;27(1):61-7.

14. LaCross A, Groff M, Smaldone A. Obstetric anal sphincter injury and anal incontinence following vaginal birth: a systematic review and meta-analysis. J Midwifery Womens Health. 2015;60(1):37-47.

15. Shmueli A, Gabbay Benziv R, Hiersch L, Ashwal E, Aviram R, Yogev Y, et al. Episiotomy - risk factors and outcomes. J Matern Fetal Neonatal Med. 2017;30(3):251-6.

16. Beckmann MM, Stock OM. Antenatal perineal massage for reducing perineal trauma. Cochrane Database Syst Rev. 2013;(4):CD005123.

17. Alon R, Shimonovitz T, Brecher S, Shick-Nave L, LevSagie A. Delivery in patients with dyspareunia - A prospective study. Eur J Obstet Gynecol Reprod Biol. 2019; 237:131-6.

18. Geranmayeh M, Rezaei Habibabadi Z, Fallankish B, 
Farahani MA, Khakbazan Z, Mehran A. Reducing perineal trauma through perineal massage with vaseline in second stage of labor. Arch Gynecol Obstet. 2012;285 (1):77-81.

19. Albers LL, Sedler KD, Bedrick EJ, Teaf D, Peralta P. Midwifery care measures in the second stage of labor and reduction of genital tract trauma at birth: a randomized trial. J Midwifery Womens Health. 2005;50(5):365-72.

20. M Amorim M, Coutinho IC, Melo I, Katz L. Selective episiotomy vs. implementation of a non-episiotomy protocol: a randomized clinical trial. Reprod Health. 2017;14(1):55.

21. Dieb AS, Shoab AY, Nabil H, Gabr A, Abdallah AA, Shaban MM, et al. Perineal massage and training reduce perineal trauma in pregnant women older than 35 years: a randomized controlled trial. Int Urogynecol J. 2020;31 (3):613-9.

22. Belizán JM, Minckas N, McClure EM, Saleem S, Moore JL, Goudar SS, et al. An approach to identify a minimum and rational proportion of caesarean sections in resourcepoor settings: a global network study. Lancet Glob Health. 2008;6(8):e894-e901.

23. Betrán AP, Ye J, Moller AB, Zhang J, Gülmezoğlu AM,
Torloni MR. The increasing trend in caesarean section rates: global, regional and national estimates: 1990-2014. PLoS One. 2016;11(2):e0148343.

24. Zare O, Pasha H, Faramarzi M. Effect of perineal massage on the incidence of episiotomy and perineal laceration. Health. 2014;6(1):10-14.

25. Shahoei R, Zaheri F, Nasab LH, Ranaei F. The effect of perineal massage during the second stage of birth on nulliparous women perineal: A randomization clinical trial Electron Physician. 2017;9(10):5588-95.

26. Ugwu EO, Iferikigwe ES, Obi SN, Eleje GU, Ozumba BC. Effectiveness of antenatal perineal massage in reducing perineal trauma and post-partum morbidities: A randomized controlled trial. J Obstet Gynaecol Res. 2018;44 (7): $1252-8$

27. Mei-dan E, Walfisch A, Raz I, Levy A, Hallak M. Perineal massage during pregnancy: a prospective controlled trial. Isr Med Assoc J. 2008;10(7):499-502.

28. Hastings-Tolsma M, Vincent D, Emeis C, Francisco T. Getting through birth in one piece: protecting the perineum. MCN Am J Matern Child Nurs. 2007;32(3):158-64. 